\title{
Tourism Activities of Deaf Poles
}

\section{Authors' contribution:}

A) conception and design of the study

B) acquisition of data

C) analysis and interpretation of data

D) manuscript preparation

E) obtaining funding

\author{
Alina Zajadacz ${ }^{1 \text { A-E }}$, Joanna Śniadek ${ }^{2}$ AC-D \\ ${ }^{1}$ University of Adam Mickiewicz in Poznań, Poland \\ ${ }^{2}$ University School of Physical Education in Poznań, Poland
}

ABSTRACT

\begin{abstract}
The chief aim of the research was to identify tourism activities of Deaf Poles. The study was conducted in 2007, and it included 191 Deaf adult Poles. The research data was collected mainly on the basis of questionnaire surveys conducted with the assistance of a sign language interpreter, individual interviews, and participant observation during tourist trips. The results were used as a basis for developing a conceptual framework for creating databanks for analyzing the data. The following statistical methods were employed: statistical significance level (p) and Tourist Information Systems (TIS), adapted to the needs of sign language users. The conceptual framework is based on the idea of active participation of Deaf individuals in creating Tourist Information Systems, cooperation networks (clusters), and the potential of Information Communications Technologies (ICTs).

deaf, deaf culture, tourism activities of deaf people, Tourist Information System (TIS)
\end{abstract}

KEYWORDS

\section{Introduction}

One of the current significant trends in tourism is the attempt to create products and services that fulfill the varied, often individual needs and preferences of tourists. This is a development in response to the objectives of accessible tourism, which has become increasingly popular; accessible tourism benefits, amongst others, people with disabilities (PwD). In order for these objectives to be realized, a thorough identification of the characteristics of the tourist activity of people with particular disabilities is required. Numerous studies dedicated to the tourism habits of PwD exist; however, relatively little can be found on the specific problems faced by deaf people using sign language. This is due to several factors. First of all, as this is one type of disability that does not cause mobility issues, there is a general belief that deaf people do not encounter greater difficulties in tourist activities than the rest of society in general. Secondly, the small number of tourists using sign language means that they are hardly noticed, and the tourism industry examines the profitability of any improvements catering to this group that are implemented. This problem is further exacerbated because, invariably, deaf tourists are not particularly wealthy. An additional factor is most certainly the specific nature of deaf communities: they often organize trips themselves, leading to the perception that the need to introduce special improvements in tourism products and services catering for this group does not exist. Another significant factor is that because there are too few representatives of deaf people in the social debate, the deaf community's voice remains unheard. The result is society's lack of knowledge about deaf people's attitudes, problems, and needs. Research into the deaf community is limited by the language barrier researchers come up against: in order to discover the opinions held by deaf people, the material needed to be adapted to sign language. 
The aim of this article is to present the scope and characteristics of the tourist activities of Deaf people in Poland. A survey, with the help of a sign language interpreter to guarantee effective communication, was carried out with users of sign language, the results of which form the main source of data in this study. The results of our own studies, as well as current knowledge of the situation as found in a review of the literature available on deaf people's tourism and its determining factors, were used in order to formulate recommendations for practitioners. The conclusions, which may be applied, mostly concern the effective communication of information to tourists who use sign language. The article proposes adapting the Tourist Information System (TIS) to the needs of sign language users via information technology and to actively involve deaf people in the creation and functioning of this system. The discussion of the tourism habits of deaf people and proposals on how to activate tourism is preceded by an explanation of the key notions of deaf and Deaf while also pointing out the medical and social context of this disability.

\section{Deaf: the meaning}

The term deaf is defined in both a medical and social context. From a medical standpoint, a person is audiologically deaf or has a profound hearing loss if he/she has a pure tone average (PTA) equal to over 95 dB HL (Mazzoli et al., 2003). "Speech is not perceived" in the case of a profound hearing loss (average tone loss of between $91 \mathrm{~dB}$ and $119 \mathrm{~dB}$ ). In total hearing loss - average tone loss over $120 \mathrm{~dB}$ - nothing is perceived (International Bureau for Audiophonology BIAP, 2005). From a cultural perspective, a person is considered culturally Deaf if he/she views him/herself as belonging to a cultural minority, i.e., the Deaf community (Berbrier, 1998), and uses sign language as the primary mode of communication (WerngrenElgström, Dehlin \& Iwarson, 2003). The degree of hearing loss is not of importance. An uppercase letter "D" is sometimes used to separate the culturally Deaf from other deaf people (Rydberg, 2010). The authors of this article [in keeping with the concept formulated by Woodward (1972) and Padden and Humphries (2006)], use the lowercase deaf when referring to the audiological condition of not hearing, and the uppercase Deaf when referring to a particular group of deaf people who share a sign language. This distinction does not exist in Polish, where the word for deaf, "gluchy", is written in the lowercase. Furthermore, in the Polish language deaf "gluchy", despite being used in official titles such as the Polski Zwiazek Gtuchych (or PZG, translation: The Polish Association of the Deaf), is steadily being replaced by hearing-impaired "niesłyszący". Szczepankowski (1999) wrote that the term for hearing impaired, "niesłyszący", is now likely to become the leading term in Polish, though there are certain drawbacks. Although the prefix "nie" - (trans: no) often holds pejorative connotations, it is also similar in spelling and pronunciation to "niedostyszacy", meaning hard of hearing. Perhaps promoting the use of the term "stabostyszacy" - people with hearing loss - would improve this situation.

The term used in the title "Deaf Poles" refers to this section of hearing impaired Poles for whom sign language is the primary means of communication; therefore, this group can be treated as a minority language group. The Polish language for people deaf since birth or who lost their hearing in early childhood is a foreign language. Their mother tongue, recognized officially, is sign language (Act on Sign language and other means of communication, 2011). This fact is often the cause of problems which arise when using text to communicate with Deaf people. Sign language contains fewer words (approximately 6,000-7,000 signs) and, as with any foreign language, has its own grammatical structure, which leads to difficulties Deaf people experience in understanding written text (especially if it contains abstract notions). A common language and shared social experience, connected both to interpersonal relations with the hearing section of society and to access to education and the labor market, create the ties that bind Deaf culture. The paper presents the responses of Deaf people who accept they are a part of the Deaf community through their membership in the PZG. The conclusions reached in the final section regarding adapting the Tourist Information System to the requirements of sign language users are universal. Their implementation may result in easier access to tourist information for all who use sign language as their main or additional mode of communication regardless of the degree to which they feel part of the Deaf community. 
It is important to take into account recent changes in the way disability is viewed, as well as the relative nature (i.e., occurring only during contact with hearing people) of the disability of Deaf people.

Existing theories of disability - both radical and mainstream - are no longer adequate. Both the medical and social models seek to explain disability universally, and end up creating totalizing, meta-historical narratives that exclude important dimensions of disabled peoples' lives and of their knowledge. The global experience of disabled people is too complex to be rendered within one unitary model or set of ideas (Corker \& Shakespeare, 2006, p. 15).

Although globally the Deaf community is highly varied, sign language is an unquestionable bond cementing Deaf culture, and is used as a natural mode of communication (Fraser \& Supalla, 2009; Goodstein, 2006). Deaf individuals are characterized by a common social experience stemming from, among other things, the feeling of being different (Goffman, 1963; Daruwalla \& Darcy, 2005). In the case of Deaf individuals, this experience is linked to an extremely difficult language barrier to overcome, understood as

"those obstacles, hindrances, or impediments that make difficult or limit the freedom of access and communication of those people whose capacity of relating to their environment through audition and oral language is limited temporarily or permanently" (Pinedo Peydró, 2009, p. 259).

The disability of Deaf people is to a great extent of a social nature. The language barrier may prevent such individuals from receiving an appropriate education or getting an attractive job, and, as a result, it may affect their economic status. Fellinger et al. (2005) state that over the last 50 years the level of education attained among this group of people has improved considerably, yet not to such a great extent as with hearing individuals.

"There are differences between the deaf and the reference population regarding level of educational attainment, position on the labor market and sources of revenue and disposable income, with the deaf population having a poorer position than the reference population in all areas" (Rydberg, 2010, p. 5).

\section{Literature review}

\section{Tourism activities of deaf people and their determinants}

In Poland, the Deaf community, which uses Polish Sign Language (PSL), consists of approximately 45,000-50,000 individuals. There have been studies of the tourism activities of Deaf Poles (Hendzel, 2000; Skalska, 2004). It has been shown that in the case of this particular social group, travel for the purposes of tourism is very rare. Therefore, one cannot speak of mass tourism among these individuals, even though hearing impairment does not prevent an individual from engaging in various forms of tourism activities, including adventure tourism. It has also been shown that Deaf Poles travel for the purposes of tourism less frequently than physically impaired or blind individuals (Skalska, 2004). The principal limitation among disabled people is their low income.

Fellinger et al. (2005) claim that Deaf individuals spend most of their leisure time within their own culture. Seeking people similar to oneself and affiliating with homogenous groups are natural social phenomena that provide for a sense of safety and stability. Lifestyle similarities and geographical proximity that allow for frequent contact are considered basic elements that influence the creation of social groups (Oyster, 2002). The lifestyle of a given group is also the basis for the segmentation of the tourism market. Characteristics representing the culture of the hearing impaired group, including from the perspective of Deaf people themselves, are illustrated in a great deal of literature (Atherton, 2007; Corker, 1996; Goodstein, 2006; Ladd, 2007; Padden \& Humphries, 2006; Young, Ackerman \& Kyle, 2000; Woodward, 1972; Zajadacz, 2010a; Zajadacz, 2012a,b). A varied range of Deaf people's environments emerges, thus displaying an interest in actively participating in social life that includes sport and tourism recreation. A good example of this type of activity was illustrated by Oliva (2006) regarding an American society where Deaf 
fathers organized recreational activities for both Deaf and hearing children in a public place. Oliva (2006) has shown that active participation of Deaf people in organizing leisure activities affects their personal satisfaction and experience of a sense of "flow" (Csikszentmihalyi, 1990, 2005). Whether a Deaf individual can experience a high sense of well-being depends primarily on his/her personal attitude and the degree to which his/her deafness is accepted. Ladd (2003) introduced the term deafhood, understood not as a

"finite state but as a process by which Deaf individuals come to actualize their Deaf identity, positing that those individuals construct that identity around several differently ordered sets of priorities and principles, which are affected by various factors such as nation area and class" (Ladd, 2003, p. xviii).

\section{Adapting tourist opportunities to the needs of deaf people}

Of primary importance when adapting tourist opportunities to the needs of Deaf individuals is to eliminate the language barrier. The TIS ought to take into account both sign language and visual perception capabilities. Research focusing on the availability of tourist products and services to disabled individuals, including Deaf people, showed that the TIS has some shortcomings, i.e., it inadequately provides for the needs of disabled tourists (Ray \& Ryder, 2003). Eichorn, Miller, Michopoulou, and Buhalis (2008, p. 192) argue "it is both the amount of research that is lacking and the absence of a theoretical framework for an improved understanding of the subject."

Of key importance in the "Framework of Interrelated Need Components" are reliable and up-to-date sources of information. Information Communication Technologies (ICTs) are opening up the possibilities in which information can be delivered. This development also enables people to create platforms where it is possible to share experiences and exchange information between potential or actual tourists (customers), as well as among clients and providers of tourist services. Such an exchange of knowledge and experience augments the TIS and consequently improves customer-orientated services that have been adapted to a range of disabilities as well as providing a greater availability of places, tourist attractions, or tourist services.

Buhalis and Michopoulou (2010) demonstrate that the accessibility market is not homogenous, but is made up of different sub-segments with distinct needs and requirements. Ultimately each person is unique in his/her abilities and preferences and this is more evident in the accessibility market. In their study, the authors have demonstrated that the predominant requirements of these segments focus on three interlinked elements: an accessible environment, information regarding accessibility, and available information online. ICTs can assist tourist destinations to address the particular requirements of these market segments effectively through the use of profiling and personalization features, which will allow users to specify their own requirements.

Numerous guidelines for tourist managers regarding the rules of making tourist opportunities available to Deaf visitors have been outlined in studies. These guidelines serve as a background exemplifying good practice (Newman, 1996; Department of Culture, Arts and Leisure, 2003; United Kingdom Council on Deafness, 2005; Bell, Findlay \& Montarzino, 2006). With particular reference to Poland, Zajadacz (2010a) proposed a system of actions intended to make tourist opportunities available to users of PSL that includes: (a) qualifications of front-line staff dealing with tourists; (b) ICTs, including Thetos - the PSL Translator (Romaniuk, Suszczanska \& Szmal, 2009; Zajadacz, 2010b).

\section{Purposes of research}

The chief aim of the research was to identify tourism activities of Deaf Poles, as well as to develop a conceptual framework for increasing the availability of tourist products and services to sign language users. Since the most common barrier preventing people from going on trips - a lack of funds - is characteristic of both Deaf individuals and Poles in general (though it is not linked to any particular type of disability), we turned our attention to communication barriers that are specific to Deaf individuals. On the basis of research 
findings we present our propositions for overcoming communication barriers through the creation of an effective TIS, which both Deaf individuals and tourist managers would find useful. The whole concept concentrates on creating a database and particularly its structure, as well as links between all the concerned parties.

The paradigm that the TIS should be orientated towards the clients' individual needs incorporated a number of specific tasks intended to determine the tourism activities of Deaf Poles. The subject of the study was the identification of: a) ways of spending free time during trips: during weekends, on public and religious holidays, and during a vacation, b) the main factors involved in the selection of tourist destinations, c) sources of tourist information, d) suggestions made by Deaf individuals on how to adapt tourism opportunities to their expectations and needs. The ways in which leisure time was spent during tourist trips were analyzed with reference to the profile of the research sample, as well as using cluster analysis (to identify the various types of tourism activities).

\section{Methods}

The research data was collected on the basis of questionnaire surveys and individual interviews conducted with Deaf Poles as well as participant observations carried out among them between 2007 and 2009. The selection of a sample group for the questionnaire interviews was conditioned by access to Deaf participants.

The questions were checked for linguistic accuracy by Deaf people, and pilot studies were conducted on a small sample ( 20 people) to modify the questions included in the forms. Most of the questions were of closed type (with a cafeteria-style checklist given), but open-ended questions were also included. Furthermore, respondents were encouraged to share their opinions, in particular with regard to how to better adapt tourist products and services to their expectations. As the aim was more to identify trends in tourism characteristics rather than the identification of behaviors in a tightly defined period (i.e., during the year previous to the study), the questions were very general, referred to typical situations (usually occurring). The presented results cannot therefore be directly compared to the data on the tourism of Poles gathered by bodies such as the Central Statistical Office or the Institute of Tourism in Warsaw.

Data on the number of Deaf individuals in Poland is only approximate. This is due to the lack of statistical reports on socio-demographic traits of the general population. This made it impossible to select a stratified sample. An assumption had been made that the questionnaire surveys would be conducted in all the provinces, in all the branches of the PZG, and should include the largest number of respondents possible. The questionnaire forms were sent by mail to all the PZG centers. Between March and September 2007, all adult members of the Association had the opportunity to take part in the survey. Interviews were conducted with the assistance of a sign language interpreter. Deaf individuals who were not members of the PZG were not included.

Individual and group interviews with Deaf people were conducted over a span of four weekend trips around the Wielkopolska region between 2007 and 2009. From seven to nine people participated in each visit. A participant observation of the behavior of Deaf tourists was also completed. Another important source of information was the personal experience of Zajadacz, gained on the basis of everyday contact with prelingually deaf individuals. The data collected on the basis of individual interviews, group interviews and participant observation was used to interpret the results of the questionnaire surveys, as well as to develop a conceptual framework for the creation of a TIS databank adapted to the needs of Deaf individuals.

\section{Participants}

The group of respondents $(n=191)$ was mainly composed of individuals who have been deaf from birth (Table 1). For most of them, the basic mode of communication used on a daily basis is PSL, as well as lipreading; one-third of the respondents use oral speech, and one-fifth use the mixed oral-sign language system. 
The respondents represented 14 out of the 16 Polish provinces. The spatial distribution was fairly even. The largest number of respondents was comprised of residents of the Świętokrzyskie Province (9\%), followed by the provinces of Silesia, Łódź, and West Pomerania (8\% each). No questionnaire forms were returned by respondents from the Kujawy-Pomerania and the Sub-Carpathian Provinces.

Table 1. Profile of the research sample

\begin{tabular}{lrlr}
\hline Traits & \% $^{*}$ & Traits & \% $^{*}$ \\
\hline Sex & & Self-assessment of financial standing & \\
women & 53 & good & 32 \\
men & 47 & average & bad \\
& & Self-assessment of health condition & 54 \\
Age & 9 & good & 36 \\
15-24 years & 40 & average & 56 \\
25-44 years & 40 & bad & 5 \\
45-64 years & 11 & & \\
65 years and more & & Period when hearing was lost & \\
Education & 5 & from birth & 57 \\
elementary & 50 & childhood & 19 \\
basic vocational & 29 & 4-7 years & 11 \\
secondary & 2 & 8-16 years & 5 \\
higher undergraduate & 8 & adult age & 4 \\
higher postgraduate & & Declared degree of hearing impairment & \\
Employed & 51 & moderate & 45 \\
yes & 46 & severe & 21 \\
no & & profound & 26 \\
\hline
\end{tabular}

*The percentage doesn't sum to $100 \%$ due to lack of answers given.

Source: survey research, A. Zajadacz 2007.

\section{Procedures and data analysis}

The following methods of statistical analysis were employed: percentage distribution, statistical significance level $(\mathrm{p}<0.05)$, and cluster analysis. All calculations were performed using the STATISTICA program.

Cluster analysis is a data analysis tool used to group objects (in our case - variables) into non-empty, disjoint, and as "uniform" as possible subsets - clusters. The objects in each cluster share a common trait (this "resemblance" is determined using various similarity measures, or rather dissimilarity measures); objects classified into different groups should be as dissimilar to each other as possible. The main objective of this analysis is to partition a data set into "natural" subsets, i.e., clusters that can be reasonably interpreted. In this study, the method of hierarchical clustering was used, which involves linking more and more objects together and aggregating larger and larger clusters of elements. Hierarchical clustering uses the dissimilarities or distances between objects when forming the clusters. Numerous methods for linking objects are used. The distance measure used in this study is the percentage disagreement determined by the percentage of dissimilar variables, and 1-r, where $r$ is the Pearson's correlation coefficient between the variables. The methods applied for linking objects were the unweighted pair-group average and Ward's method. In the former method, the distance between two clusters is calculated as the arithmetic average distance between all pairs of objects in the two different clusters. The latter method uses an analysis of the variance approach to evaluate the distances between clusters; it attempts to minimize the Sum of Squares (SS) of any two clusters that can be formed at each step. The following amalgamation algorithm is used:

- In step one, each object represents its own cluster.

- The two clusters that are closest (in terms of the chosen dissimilarity measure) are combined into a new aggregate cluster, thus reducing the number of clusters by one.

- The second step is repeated until all objects are grouped into one large cluster. 
To illustrate the arrangement of the clusters produced by hierarchical clustering, a dendrogram is used. It is a tree diagram with nodes representing the clusters, and leaves representing the particular objects. The leaves are placed at the zero level, and the nodes are placed at the level corresponding to the dissimilarity measure between clusters represented by descendant nodes.

\section{Results}

\section{Tourism activities at weekends and on public and religious holidays}

Most of the respondents (71\%) declare that they travel for recreational and tourist purposes at weekends and on public and religious holidays, while nearly a quarter (23\%) state that they do not engage in such activities. Deaf people's tourism activity is similar to that of hearing people (see Zajadacz, 2012a). A statistically significant factor in this particular case is the manner of communication (Table 2). Individuals who communicate not only in PSL travel more often. Additionally, the level of income is a significant factor, as indeed it is for the majority of Poles. In this case the interdependency observed is directly proportional (Institute of Tourism, 2009; Central Statistical Office, 2009). The largest group (22\%) includes people who several times a year go on trips for the purposes of tourism and recreation; of this group, one in four travels twice a month. At weekends and on public and religious holidays, most of the respondents spend their free time with their friends or families; $13 \%$ spend time alone. In the majority of cases, respondents visit friends and relatives, or go to the countryside, seaside, or lakeside (Table 3). Visiting friends and relatives is also one of the most popular reasons for a trip for the majority of Poles for short domestic excursions (Institute of Tourism, 2009). A particular feature specific to Deaf people is that visits to Deaf friends were indicated as the reason for a trip more often than a visit to hearing people or fa mily. This reflects the desire among Deaf people to spend time within their own social circle, guaranteeing easy communication, which in turn affects their sense of well-being.

Table 2. Recreational trips made at weekends and on public and religious holidays

\begin{tabular}{|c|c|c|c|c|}
\hline \multirow[t]{2}{*}{ Trait } & \multicolumn{4}{|c|}{$\begin{array}{l}\text { Does he/she go on recreational trips on } \\
\text { Saturdays, Sundays, and public and } \\
\text { religious holidays? - positive answer }\end{array}$} \\
\hline & Estimate & Std. Error & Wald Stat. & $\mathrm{p}$ \\
\hline Sex & 0.48 & 0.5 & 0.93 & 0.33 \\
\hline Age & -0.36 & 0.36 & 0.97 & 0.32 \\
\hline Education & 0.17 & 0.33 & 0.15 & 0.70 \\
\hline Employed & -0.35 & 0.58 & 0.36 & 0.55 \\
\hline Marital status & 0.06 & 0.55 & 0.01 & 0.92 \\
\hline Financial standing & -0.79 & 0.52 & 2.32 & 0.13 \\
\hline Number of family members: adults & -0.06 & 0.36 & 0.03 & 0.86 \\
\hline Number of family members: children & 0.62 & 0.35 & 3.16 & 0.08 \\
\hline Income & 0.8 & 0.42 & 3.63 & 0.06 \\
\hline Health condition & -0.4 & 0.49 & 0.66 & 0.42 \\
\hline Way of communicating & -1.53 & 0.77 & 3.99 & 0.05 \\
\hline Age when lost hearing & -0.42 & 0.33 & 1.6 & 0.21 \\
\hline Cause of hearing impairment & 0.08 & 0.57 & 0.02 & 0.88 \\
\hline Degree of hearing impairment & 0.31 & 0.28 & 1.18 & 0.28 \\
\hline Can other family members hear? & 0.13 & 0.59 & 0.05 & 0.83 \\
\hline
\end{tabular}

Source: survey research, A. Zajadacz 2007.

Based on the cluster analysis of various forms of leisure activities, it is possible to distinguish four types of recreational behaviors exhibited during trips made at weekends and on public and religious holidays (Figure 1):

- the "oriented on knowledge, relaxation and entertainment" group - individuals who like watching TV (including programs with sign language interpretation), and at the same time enjoy reading newspapers, magazines, and books, doing crossword puzzles, working in the garden, and DIY activities; 
- the "oriented on family and society" group - individuals who usually spend their free time with their families, visiting relatives, meeting friends (both hearing and hearing-impaired, including meetings organized by the PZG), going on trips and for walks;

- the "oriented to contemplation" group - individuals who enjoy going to church and attending religious meetings, but also like spending their free time on the computer;

- the "oriented to culture and entertainment" group - individuals who like going to the theater or cinema, visiting art galleries, and going to cafés and pubs.

Table 3. Forms of spending free time at weekends and on public and religious holidays (outside the place of residence)

\begin{tabular}{llll}
\hline Forms of leisure activity & \% & Forms of leisure activity & $\%$ \\
\hline Meeting deaf friends & 36 & Reading newspapers and magazines & 12 \\
Walks & 33 & Religious meetings & 12 \\
Trips & 27 & Visiting art galleries and exhibitions & 11 \\
Meetings organized by the PZG & 25 & Doing crossword puzzles & 10 \\
Meetings with hearing friends & 24 & Reading books & 9 \\
Visiting relatives & 24 & DIY & 8 \\
Spending time with the family & 20 & Going to the theatre & 7 \\
Going to cafés and pubs & 16 & Watching TV (all channels) & 6 \\
Praying in church & 14 & Watching TV (only programs with sign & 6 \\
& & language interpreting) & \\
Working in the garden & 13 & In front of a computer & 5 \\
Going to the cinema & 13 & Other & 2 \\
\hline Source: survey resing
\end{tabular}

Source: survey research, A. Zajadacz 2007.

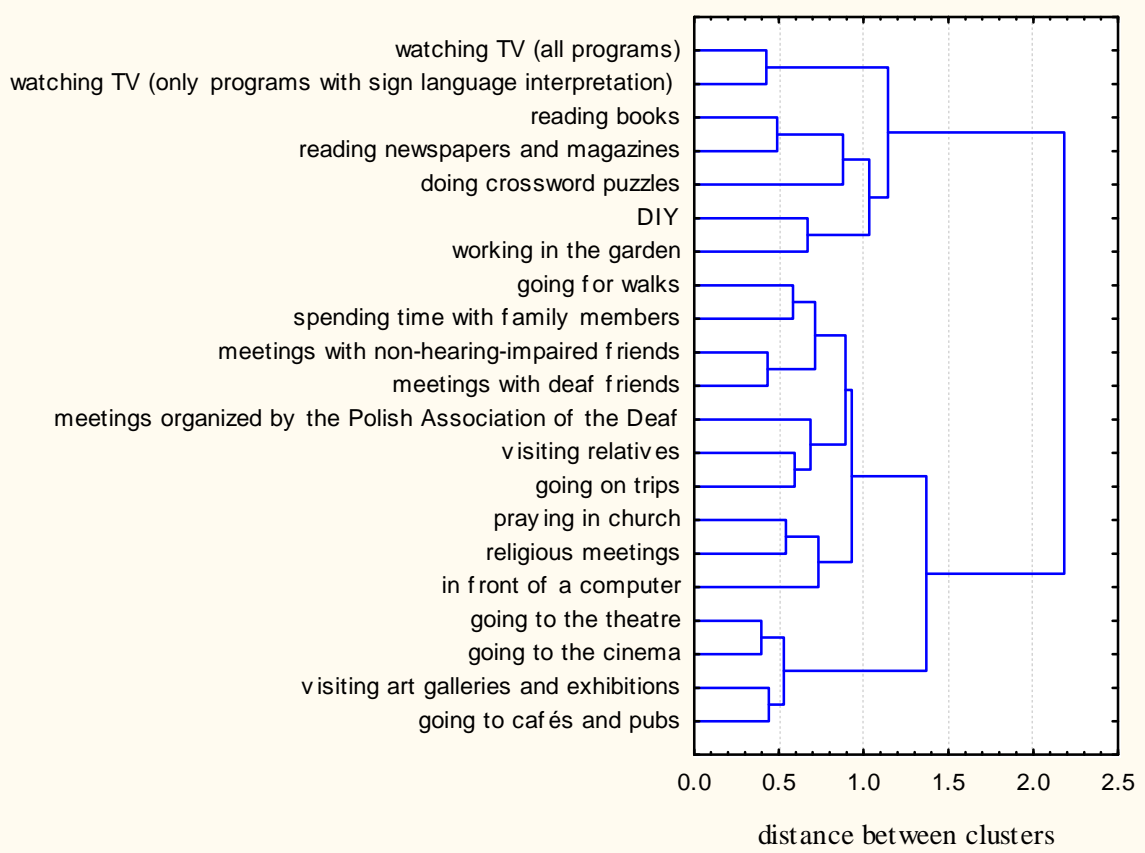

Figure 1. Forms of leisure activity pursued at weekends and on public and religious holidays (outside the place of residence) - cluster analysis, method of amalgamation: Ward's method, distance measure 1-r Source: survey research, A. Zajadacz, 2007.

If not for the existing barriers, going on trips would be the preferred form of spending free time on weekends and on public and religious holidays (Table 4). This is proof that Deaf people are very interested in traveling for purposes of tourism, especially in connection with sightseeing, where landscapes or exhibitions are the primary elements. However, there is less participation in events in which part of the information is delivered in audio format. Traveling for tourism is a significant source of information for users of sign language. A barrier preventing access to information, such as the use of a different language, makes gathering information much more difficult, and sharing such information with other Deaf people is a 
significant factor creating ties between members of the Deaf community. Tourism, as with the majority of society, is also an indicator of social prestige. The creation of tourism products and services accessible to sign language users is therefore a way in which this group's participation in society can also be increased. Any action undertaken related to this should include, above all, the breakdown of the following barriers: 1 . Economic: in regards to participation in tourism (low income is the main reason why Deaf people do not travel, as it is the same for the general public in Poland), 2. Linguistic: by adapting the Tourist Information Service to the needs of sign language users, 3. Psychological: as positive customer service attitudes to finding the best means of communication and creating a welcoming atmosphere is the most straightforward way in which to encourage this particular group of clients to make more use of tourism services.

Table 4. Preferred forms of leisure activity pursued during trips made at weekends and on public and religious holidays

\begin{tabular}{lr}
\hline Form of leisure activity & $\%$ \\
\hline Trips (sightseeing, going to the countryside, walking in the mountains, going to the seaside, going to a lake, \\
communing with nature, going to the forest, pilgrimages, cycling trips, going on trips with friends, \\
travelling abroad) & 27 \\
Relaxation (at home, in peace and quiet) & 7 \\
Meeting friends and family members & 5 \\
Lazing about & 5 \\
Active leisure pursuits (walks, engaging in sports activity) & 4 \\
Working in the garden & 3 \\
Watching TV & 2 \\
Watching sports events, matches & 2 \\
Hobbies (taking photographs, painting, cooking) & 2 \\
Fishing & 2 \\
Sleeping & 1 \\
Reading & 1 \\
\hline
\end{tabular}

Source: survey research, A. Zajadacz 2007.

\section{Tourism activities undertaken during vacations}

Nearly three-quarters $(73 \%)$ of the respondents declare that they travel for recreational and tourism purposes during a vacation, and more than half travel for this reason every year or several times a year. There is little difference in activity levels in terms of tourism during vacations and holidays between Deaf and hearing people (see Zajadacz, 2012a). Statistically significant factors (Table 5) that influence decisions pertaining to tourist trips include (as in the case of weekends and public and religious holidays): the way of communicating and the degree of the hearing impairment (inversely proportional relationship).

Table 5. Tourist trips made during a vacation

\begin{tabular}{lrrrr}
\hline Trait & \multicolumn{4}{r}{ Does he/she go on vacation? - positive answer } \\
& Estimate & Std. Error & Wald Stat. & $\mathrm{p}$ \\
\hline Sex & -0.16 & 0.57 & 0.08 & 0.78 \\
Age & -0.69 & 0.41 & 2.82 & 0.09 \\
Education & 0.19 & 0.41 & 0.22 & 0.63 \\
Employed? & 0.98 & 0.63 & 2.41 & 0.12 \\
Marital status & 0.06 & 0.63 & 0.01 & 0.93 \\
Financial standing & -0.77 & 0.55 & 1.93 & 0.16 \\
Number of family members: adults & 0.21 & 0.41 & 0.27 & 0.60 \\
Number of family members: children & -0.23 & 0.35 & 0.41 & 0.52 \\
Income & 0.47 & 0.41 & 1.31 & 0.25 \\
Health condition & -0.52 & 0.55 & 0.88 & 0.35 \\
Way of communicating & -1.73 & 0.88 & 3.85 & 0.05 \\
Age when lost hearing & -0.15 & 0.36 & 0.18 & 0.67 \\
Cause of hearing impairment & -0.48 & 0.65 & 0.53 & 0.47 \\
Degree of hearing impairment & 0.71 & 0.34 & 4.34 & 0.04 \\
Can other family members hear? & -0.24 & 0.66 & 0.13 & 0.72 \\
\hline Source: survey insearch, A.Zajadacz
\end{tabular}

Source: survey research, A. Zajadacz, 2007. 
Respondents most often travel to visit their relatives or go to the seaside, mountains, countryside, or a lake. Equally numerous groups of individuals (15\%) stated that they go abroad or stay at sanatoriums. In the case of 26 respondents, the furthest they have ever traveled in their lives was to domestic destinations. A significant portion (85 out of 191 individuals) mentioned European countries, in particular those located in southern Europe: France, Italy, and Croatia. Only a few people have visited other continents: four individuals have been to North America, six to northern Africa, and two to Asia. These answers concerned the furthest they have been for purposes of tourism in their lifetime; it is thus impossible to compare this with the data on foreign travel of Poles held by the Central Statistical Office or the Institute of Tourism in Warsaw, as their data concern tourist travel on a scale of a given year. However, it is clear that the most popular foreign destinations Deaf people mention are amongst the most popular holidays abroad for Polish tourists in general (Institute of Tourism, 2009). The destinations are also on the list of the most popular tourist hotspots in terms of numbers of foreign visitors - France has been number 1 for years, Italy number 5 (UNWTO, 2010).

\section{Main factors influencing decisions regarding the choice of tourist destinations}

The most important factors influencing decisions pertaining to the choice of tourist destination indicated by the respondents included: price, easy access, good opportunities for improving one's health, beautiful scenery, and the opportunity to be in the company of Deaf people. Rarely is the main motive for taking a trip a cultural event. In the case of the general public overall in Poland (Zajadacz, 2012a), the number one factor is also the cost of the holiday, followed by lovely scenery, attractive natural surroundings, discovering new places and differences with regards to normal everyday surroundings. It has been observed that safety concerns regarding accessibility and security of destinations are more important within the Deaf community, as is spending time with other Deaf people.

Based on cluster analysis of the most significant factors influencing decisions relating to the choice of tourist destination during a vacation, it is possible to distinguish four groups of motives and an individual factor (occurring most often), i.e., price (Figure 2).

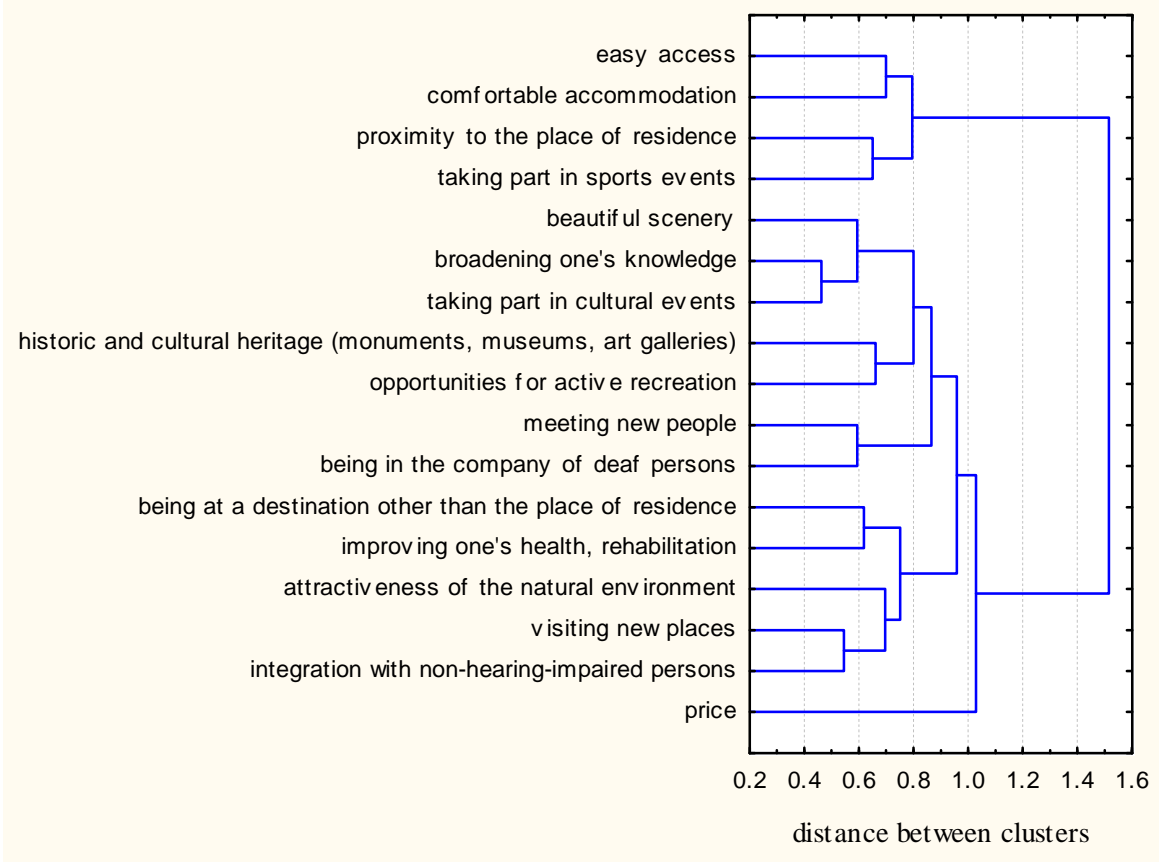

Figure 2. The most significant factors influencing decisions pertaining to the choice of tourist destination - cluster analysis, method of amalgamation: Ward's method, distance measure 1-r

Source: survey research, A. Zajadacz, 2007. 
Within these groups, the following types can be singled out:

1. The "oriented to comfort" group - individuals who are attracted by easy access, comfortable accommodations, proximity to the place of residence, and opportunities for partaking in sports events;

2. The "oriented to communing with nature, learning the culture and people, and active recreation" group - individuals for whom the most important aspects are: beautiful scenery, broadening one's knowledge, taking part in cultural events, historic and cultural heritage, opportunities for active recreation, meeting new people and the opportunity to be in the company of Deaf people;

3. The "oriented to health and recreation" group - individuals for whom the most important aspects are: improving one's health, rehabilitation, being at a destination other than their place of residence, and attractiveness of the natural environment;

4. The "oriented to visiting new places and integration with hearing persons" group.

The most popular forms of spending free time by Deaf individuals during a vacation are: walking and sightseeing, followed by swimming, sunbathing, and observing nature (Table 6).

Table 6. Forms of spending free time during a vacation

\begin{tabular}{llll}
\hline Forms of leisure activity & $\%$ & Forms of leisure activity & $\%$ \\
\hline Walks & 70 & Rehabilitation stays & 30 \\
Sightseeing & 48 & Working in the garden & 21 \\
Swimming & 39 & Taking part in rallies and hikes & 15 \\
Sunbathing & 39 & Going on pilgrimages & 12 \\
Watching the nature & 38 & Farm tourism & 12 \\
Cycling & 34 & Skiing & 8 \\
Reading & 34 & Sanatorium stays & 6 \\
Watching TV & 33 & Hobbies & 5 \\
Walking in the mountains & 31 & Sailing & 4 \\
Taking photographs & 30 & Other & 3 \\
\hline Source:
\end{tabular}

Source: survey research, A. Zajadacz, 2007.

Based on cluster analysis of the forms of spending free time during a vacation, it is possible to distinguish the following groups of interrelated activities and pursuits: 1. walking and taking photographs, 2. swimming and sunbathing, 3. walking in the mountains, cycling, skiing, and taking part in rallies and hikes, 4. agro tourism, sanatorium stays, and sailing, 5. watching TV, working in the garden, going on pilgrimages, and rehabilitation stays, 6. sightseeing, observing nature, and reading (Figure 3). As far as preferred forms of leisure are concerned, they reflect the observed trends observed for the general Polish public (Zajadacz, 2012a). The significant differences are mainly connected to Deaf people taking part in pilgrimages, rallies, and rehabilitation camps, which indicate a higher tendency to participate in organized forms of leisure.

The most popular source of information concerning tourist trips is the Internet (29\%), followed by family recommendation (26\%), newspapers and travel agencies (11\% each), guidebooks (7\%) and tourist information offices $(6 \%)$. The fact that Deaf people turn to information contained in newspapers more frequently (classified advertisements) and refer to guidebooks less often (in which the content, due to language differences, may be difficult to understand) is significant.

\section{Suggestions from deaf people on how to better adapt tourism products and services to their needs}

The suggestions made by the respondents mainly concerned possibilities both for obtaining relevant information when preparing a trip and for having opportunities for communicating in Polish Sign Language during a trip (22\%). Another group of suggestions referred to adjusting the price of tourism products and services in order to take into account the financial means of Deaf individuals (cheaper trips; 15\%). A wider problem was also identified, i.e., the low financial status of Deaf people resulting from poor educational opportunities and unfavorable conditions on the labor market (10\%). Numerous respondents mentioned the use of visual means to provide information (graphic symbols, plans, and drawings), simple texts which users 
of Polish Sign Language would find easier to understand, and extending the use of Information Communication Technologies (ICTs). Another point raised by respondents was the necessity for a change in the attitude of the state and society towards Deaf individuals, combating discrimination, and better advocacy of tourism among Deaf people.

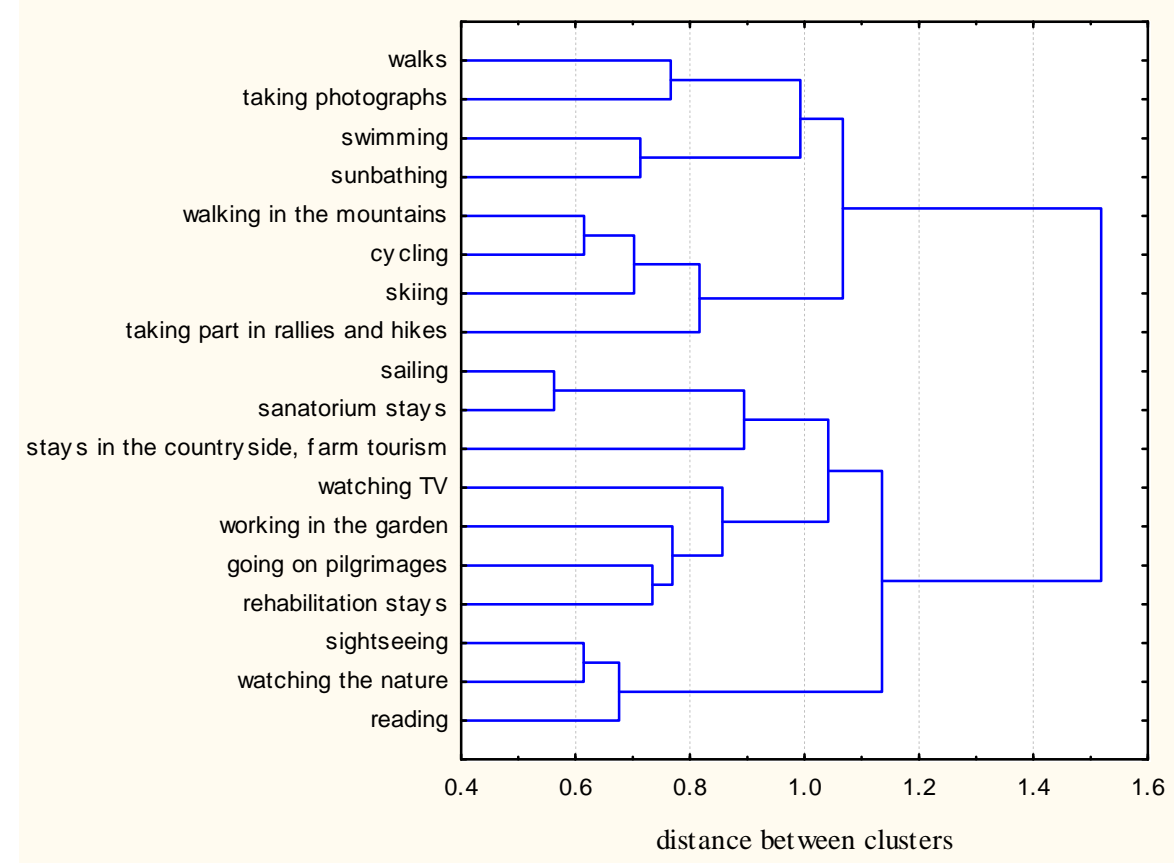

Figure 3. Forms of spending free time during a vacation - cluster analysis, method of amalgamation: Ward's method, distance measure 1-r

Source: survey research, A. Zajadacz, 2007.

\section{Findings}

The results of the research carried out in the Deaf community where communication was made easier thanks to cooperation with sign language interpreters indicated that tourist activity (understood as travel for purposes of tourism) does not differ significantly from the group representative of Polish society in general. The conclusion made in previous studies that Deaf people rarely travel for tourism was therefore unconfirmed. However, the responses from Deaf participants revealed certain characteristics in the type of tourist trips taken as well as indicating the direction to follow to better tailor tourist products and services to their needs. Apart from wide-ranging action concerning improving the economic status of Deaf people in relation to society in general, the Tourist Information System and the customer service attitudes of personnel in the tourism sector should be the focus of attention.

Deaf users of PSL constitute a varied subgroup of tourists. Their interest in travel for purposes of tourism is indicative of a high demand for tourism products and services appropriately adapted to their individual needs. The exchange of knowledge and experiences between Deaf individuals and tourism managers, based on a cooperation network, is a basis for adapting tourist opportunities to the specific preferences of individual Deaf clients. As a result, a segment of clients can be won over by the tourism industry that it has thus far neither duly recognized nor appreciated. Introducing these rules when creating TIS databanks would encourage Deaf individuals to envision their dreams and go on individual trips. Highquality tourism products and services, adapted to the needs of the studied subgroup, afford satisfaction and make it possible for the subjective "feeling of flow," the essence of tourism activities, to be experienced. The results of studies truly stress the need to familiarize tourism managers and front-line staff dealing with Deaf tourists with sign language; they also show the need to train Deaf people in professions linked with the tourism industry. 


\section{Conclusions}

The results of the study confirm that while most of the participants enjoy spending their free time with hearing persons, a tendency towards social isolation was observed, which particularly holds true for the culturally Deaf. The research therefore confirms the observations made by Fellinger et al. (2005). Deaf people who live among hearing family members are more likely to be more socially open and active. Hence, it is possible to conclude that integrating Deaf individuals into a group of individual recipients of tourist products and services will be possible if hearing members of society become more aware of the needs of Deaf individuals regarding communication.

On the basis of relevant literature (Oliva, 2006; Eichorn, Miller, Michopoulou \& Buhalis, 2008; Buhalis \& Michopoulou, 2010) and the results of conducted research a conceptual framework for creating a TIS databank was developed. It was assumed that such a database should be based on:

- the results of research on tourism activities of Deaf individuals, conducted on a cyclical basis (identification of current trends, forecasting tourist demand);

- the active participation of Deaf individuals in its creation and functioning;

- cooperation between the main parties involved its creation, operation and development, including: Deaf individuals, representatives of the tourism sector (tour operators and managers of tourist facilities), Deaf support groups, those involved in promoting tourism domestically or regionally, representatives of scientific centers conducting cyclical research on tourism activities of Deaf people;

- the use of ICTs.

Each of the parties concerned responsible for providing up-to-date information could use a common databank for its specific purposes. Such a database ought to function domestically and regionally as part of TIS. A significant link in the proposed structure of the TIS databank is scientific centers that ought to conduct cyclical research on tourism activities of Deaf people. To facilitate monitoring the tourism activities of Deaf individuals, cooperation should be established with institutions operating in their immediate vicinity (open to Deaf individuals or rendering services to them). Deaf individuals participating in the research should be informed of the results as soon as possible. Feedback information offered to respondents is a motivating factor that in the future will involve them more deeply in upcoming research. When participants realize that the results prove to be practical and include improvements to their own situation, they will be eager to cooperate. Offering access to reports of conducted research on Deaf individuals (also using such distribution channels as institutions operating in their immediate vicinity) creates an atmosphere of positive and long-lasting cooperation (Figure 4).

The results of systematic academic research provide the tourism sector with information on current trends in the activities of the studied group, and make it possible to forecast tourist demand. Providers of tourism products and services are responsible for supplying up-to-date information on how and to what extent their offer is adapted to the needs of sign language users. This data forms the core of tourist information for those to whom the offer is addressed, and - as an example of good practice - other tourism managers may find it useful.

In light of the discussed concept, Deaf individuals are the main addressees of the databank, and at the same time they are its creators. They can exchange information and their experiences, as well as make recommendations to other members of the group. On one hand, the databank is uniform in regards to the mode of communication (manual); on the other hand, it is diversified in terms of tourist preferences. 


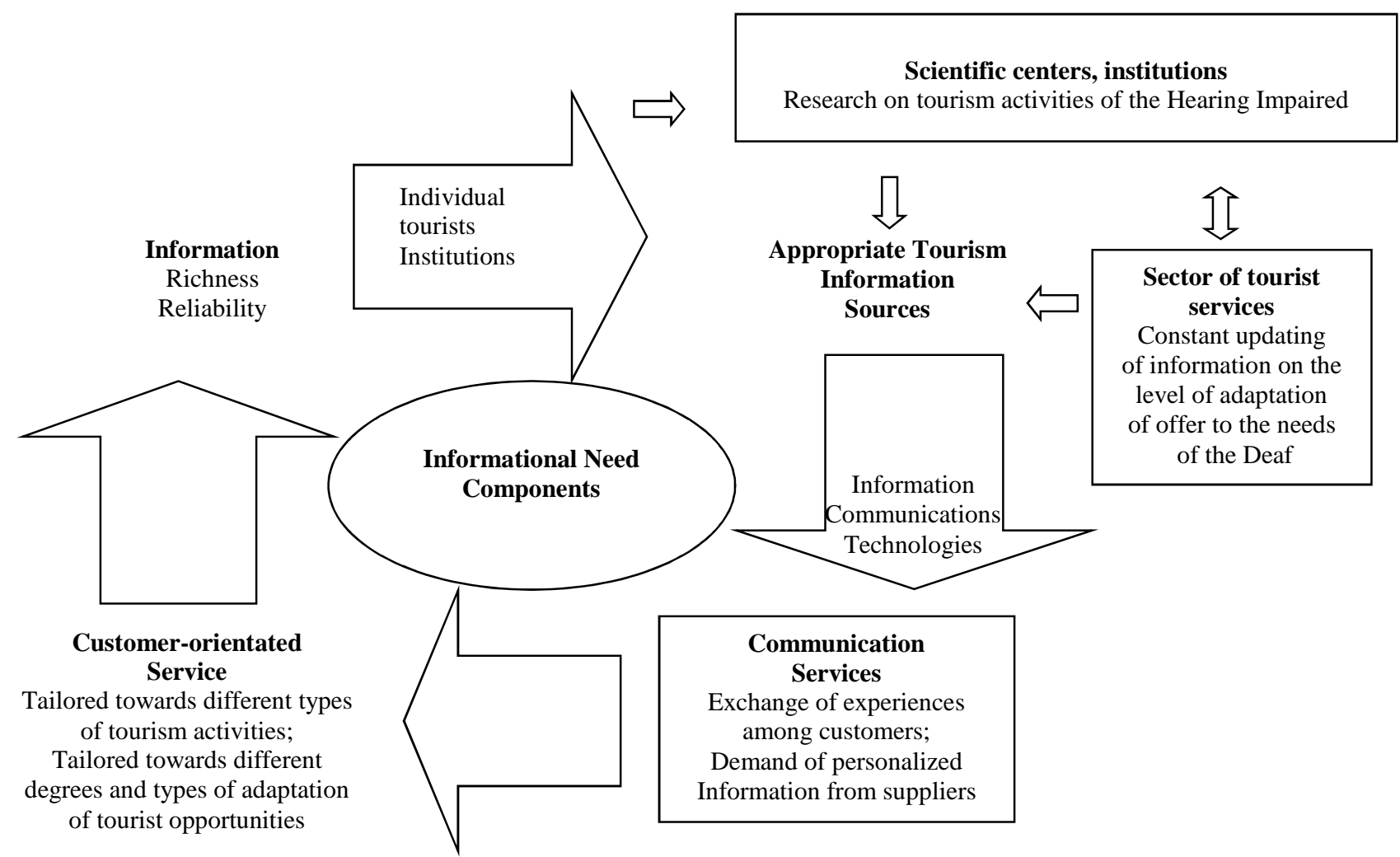

Figure 4. Structure of a TIS databank addressed to Deaf people

Source: Eichhorn, Miller, Michopoulou, Buhalis, 2008.

The proposed TIS databank is based on information collected within a cooperation network (cluster) whose main links are: scientific centers, institutions, the tourism industry, and the Deaf community. Incorporating this database into a national and regional TIS, and by using ICTs, will make it possible to build a homogenous and universal databank adapted to the diverse needs of tourists.

The comparison of the socioeconomic situation of the hearing impaired in Poland with other European countries, such as Sweden (Rydberg, 2010) or Germany (Fellinger et al., 2005), illustrates that the common characteristic of these social groups is a compilation of problems connected with their disability resulting in their low economic and social status. Gleeson's (1996) conclusion that "poverty is disability's close companion" is thereby supported. However, when compared to American Deaf people, the Polish Deaf community is definitely not active. The case study illustrated by Oliva (2006) is an example of good practice encouraging Deaf people using sign language to organize activities that would lead to greater satisfaction stemming from their leisure time. Also, the model shown in the article "Structure of a TIS databank addressed to Deaf People" should motivate the sign language speaking community to take part in the process of creating an optimal tourist offer based on a reliable and current database concerning the needs and preferences of Deaf tourists.

\section{REFERENCES}

Atherton, M. (2007). Acquiring Social Capital through Shared Deafness. Sport, Leisure, Culture and Social Capital: Discourse and Practice. LSA Publication, 100, 67-78.

Bell, S., Findlay, C., Montarzino, A., OPENspace Research Centre. (2006). Access to the countryside by deaf visitors. Scottish Natural Heritage Commissioned Report No. 171 (ROAME No. F03AB05). Retrived 10.06.2010 from http://www.snh.org.uk/pdfs/publications/commissioned_reports/f03ab05.pdf

Berbrier, M. (1998). Being Deaf has very little to do with one's ears: Boundary-Work in the Deaf Culture Movement. Perspectives on Social Problems, 10, 79-100. 
Buhalis, D., Michopoulou, E. (2010). Information-enabled tourism destination marketing: addressing the accessibility market. Current Issues in Tourism, Vol.10.6. http://www.buhalis.com/buhalis/page/publications.htm. (accessed September 20, 2010).

Csikszentmihalyi, M. (1990). Flow: The psychology of optimal experience. New York: Harper Collins.

Csikszentmihalyi, M. (2005). Przeptyw. Psychologia optymalnego doświadczenia /Flow: The psychology of optimal experience/. Taszów: Biblioteka Moderatora.

Corker, M. (1996). Deaf transitions: Images and Origins of Deaf Families, Deaf Communities and Deaf Identities. London: Jessica Kingsley Publishers Ltd.

Corker, M., Shakespeare, T. (2002). Mapping the Terrain. In M. Corker \& T. Shakespeare (Eds.), Disability/ Postmodernity: Embodying disability theory (pp. 1-17). London: Continuum.

Daruwalla, Ph., Darcy, S. (2005). Personal and societal attitudes to disability. Annals of Tourism Research, 32(3), 549570 .

Demographic Yearbook (2010). Warszawa: Główny Urząd Statystyczny /The Central Statistical Office/.

Department of Culture, Arts and Leisure. (2003). Best Practice Guidance on providing public services to deaf people who use British Sign Language or Irish Sign Language. Belfast: Department of Culture, Arts and Leisure.

Eichhorn, V., Miller, G., Michopoulou, E., Buhalis, D. (2008). Enabling access to tourism through information schemes? Annals of Tourism Research, 35(1), 189-210.

Fellinger, J., Holzinger, D., Schoberberger, R., Lenz, G. (2005). Psychosoziale Merkmale bei Gehörlosen: Daten aus einer Spezialambulanz für Gehörlose /Psychosocial characteristics of the deaf: data from a specialized clinic for the deaf/. Der Nervenarzt, 76(1), 43-51.

Fraser, B., Supalla, S. (Eds.) (2009). Deaf History and Culture in Spain: A Reader of Primary Documents. Washington, DC: Gallaudet University Press.

Gleeson, B. (1996). A Geography for Disabled People? Transactions of The Institute of British Geographers, 21, $387-$ 396.

Goffman, E. (1963). Stigma: Notes on the Management of a Spoiled Identity. Englewood Cliffs, NJ: Prentice-Hall.

Goodstein, H. (2006). The Deaf Way II Reader: Perspectives from the Second International Conference on Deaf Culture. Washington, DC: Gallaudet University Press.

Central Statistical Office. (2009). Tourism and leisure in the home in 2009. Warsaw.

Hendzel, J. (2000). Turystyka i krajoznawstwo wśród osób z uszkodzonym słuchem /Tourism and sightseeing among hearing impaired people/. In T. Łobozewicz T. (Ed.), Turystyka i rekreacja ludzi niepetnosprawnych /Tourism and recreation of the disabled people/ (pp.196-212). Warszawa: Wyższa Szkoła Ekonomiczna.

Holloway, J.Ch., Robinson, Ch. (1997). Marketing w turystyce /Marketing of tourism/. Warszawa: Polskie Wydawnictwo Ekonomiczne.

International Bureau for Audiophonology BIAP (2005). Recommendations. BIAP Recommendation $\quad n^{0} \quad$ 02/lbis: Audiometric Classification of Hearing Impairments. Liège: International Bureau for Audiophonology BIAP. Retrieved 22.10.2008 from http://www.biap.org

Institute of Tourism in Warsaw. (2009). Domestic and foreign travel of Poles in 2009. Retrieved 07.2012 from http://www.intur.com.pl

Ladd, P. (2003). Understanding Deaf Culture: In Search of Deafhood. Bristol: Multilingual Matters Ltd.

Mazzoli, M., Van Camp, G., Newton, V., Giarbini, N., Declau, F., Parving, A. (2003). Recommendations for the description of genetic and audiological data for families with nonsyndromic hereditary hearing impairment. Audiological Medicine, 1(2), 148-150.

Newman, I. (1996). BT Countryside For All: Accessibility Standards For Countryside Recreation. In G. Hitzhusen, L. Thomas \& M. Birdsong (Eds.), Global Therapeutic recreation IV. Selected papers from the Fourth International Symposium on Therapeutic Recreation (pp.119-128). Columbia: University of Missouri.

Oliva, G. (2006). The D/deaf Community, Leisure, and Public Recreation. In H. Goodstein (Ed.), The Deaf Way II Reader: Perspectives from the Second International Conference on Deaf Culture (pp.305-314). Washington, DC: Gallaudet University Press.

Oyster, C. (2002). Grupy. Psychologia społeczna /Groups. Social psychology/. Poznań: Zysk i S-ka.

Padden, C., Humphries, T. (1990). Deaf in America: Voices from a Culture. Cambridge, MA: Harvard University Press.

Padden, C., Humphries, T. (2006). Inside Deaf Culture. Cambridge, MA: Harvard University Press.

Pinedo, P.F.J. (2009). Spanish Sign Language (LSE): A True Language. In B. Fraser \& S. Supalla (Eds.), Deaf History and Culture in Spain: A Reader of Primary Documents (pp. 243-260). Washington, DC: Gallaudet University Press. 
Ray, N., Ryder, M. (2003). "Abilities" tourism: an exploratory discussion of the travel needs and motivations of the mobility-disabled. Tourism Management, 24, 57-72.

Romaniuk, J., Suszczańska, N., Szmal, P. (2009). Semantic analysis elements in the Thetos-3 system. In Z. Vetulani (Ed.), Proceedings of the $4^{\text {th }}$ Language \& Technology Conference: Human Language Technologies as a Challenge for Computer Science and Linguistics (pp. 330-364). Poznań: Wydawnictwo Naukowe UAM.

Rydberg, E. (2010). Deaf people and the labour market in Sweden: Education - Employment - Economy. Studies from the Swedish Institute for Disability Research, no. 32. Örebro University. Retrieved 22.07.2010 from http://oru.divaportal.org/smash/record.jsf?pid=diva2:310710

Skalska, T. (2004). Turystyka osób niepetnosprawnych: Ograniczenia i możliwości rozwoju /Disabled people's tourism: limitation and opportunities of development/. Warszawa: Wyższa Szkoła Hotelarstwa, Gastronomii i Turystyki.

Polish Association of the Deaf (2010). Statutory Report. Warsaw: PZG [Sprawozdanie Polskiego Związku Głuchych, Warszawa 2010].

Szczepankowski, B. (1999). Niestyszący - Gtusi - Gtuchoniemi. Wyrównywanie szans/Hearing impaired - Deaf - Deafmute. To give equal opportunity/. Wydawnictwa Szkolne i Pedagogiczne, Warszawa.

United Kingdom Council on Deafness. (2005). Deaf Awareness Week: Examples of Good Practice. Retrieved 15.11.2008 from http://www.defacouncil.org.uk/daw/goodp

UNWTO World Tourism Organization. (2001). Thesaurus on Tourism and Leisure Activities. Madrid: UNWTO.

UNWTO World Tourism Organization. (2010). World Tourism Barometer Interim Update. Madrid: UNWTO.

Act on sign language and other means of communication. Journal of Laws No. 209, item 1243 [Ustawa z 19 sierpnia 2011 r. o języku migowym i inych środkach komunikowania się. Dz.U. z 2011 r. Nr 209, poz. 1243.].

Werngren-Elgström, M., Dehlin, O., Iwarson, S. (2003). A Swedish Prevalence Study of Deaf People Using Sign Language: A prerequisite for Deaf studies. Disability and Society, 18, 311-323.

Woodward, J. (1972). Implications for sociolinguistics research among the deaf. Sign Language Studies, 1, 1-7.

Young, A., Ackerman, J., Kyle, J. (2000). On creating a workable signing environment: deaf and hearing perspectives. Journal of Deaf Studies and Deaf Education, 5(2), 186-195.

Zajadacz, A. (2010a). Czas wolny, turystyka i rekreacja osób niestyszących w Polsce /Free time, tourism and recreation of hearing impaired people in Poland/. Seria: Turystyka i Rekreacja Studia i Prace nr 4., t. IV. Poznań: Wydawnictwo Naukowe UAM.

Zajadacz, A. (Ed.) (2010b). The SITex and SITur programs as tools designed to provide information to visitors and tourists using the Polish Sign Language. Poznań: Wydawnictwo Naukowe UAM.

Zajadacz, A. (2012a). Turystyka osób niestyszanych - ujęcie geograficzne /Tourism of heairing impaired people geografical approach/. Poznań: Bogucki Wydawnictwo Naukowe.

Zajadacz, A. (2012b). Sources of tourist information used by Deaf people. Case study: the Polish Deaf community. Current Issues in Tourism, 1-21. DOI: 10.1080/13683500.2012.725713.

AUTHOR'S ADDRESS: $\quad$ Joanna Śniadek

Tourism and Recreation Faculty

University School of Physical Education

ul. Królowej Jadwigi 27-39

61-871 Poznań

Poland

Email: j.sniadek@gmail.com 